\title{
PENGEMASAN PAKET WISATA DENGAN MEMANFAATKAN POTENSI DESTINASI WISATA ALTERNATIF DI KAWASAN PANTAI PARANGTRITIS
}

\author{
Miftah Arif Fiyan \\ NIDN : 0526058602 \\ Dosen Perhotelan AKPAR "BSI \\ Yogyakarta" \\ email: miftah.mfh@bsi.ac.id
}

\author{
Hari Rachmadi \\ NIDN : 0505076501 \\ Dosen Sekolah Tinggi Pariwisata \\ AMPTA \\ email:harri.rachmadi@gmail.com
}

\begin{abstract}
Yogyakarta which has a unique culture and nature and also relics of historical and religious relics can be a point of interest for domestic and foreign tourists. With diversity is quite a lot of power. This research is why Alternative Tour Packages will be an attraction if in a pack in such a way that becomes a diverse and interesting tour packages. With qualitative descriptive research methods found in addition to the main destinations Parangtritis Beach which was first famous. With the packaging method of alternative tour packages and promotions will make the new destinations become the main and complementary destination support power for a visit in Yogyakarta. Can be condluded that Parangtritis which became the main destination for tourists domestic is a region that has the potential to be developed, this area there is destination 1.Nature 2.Religi 3.History 4.Culture but not packaged into a package of alternative tourism. Packaging Alternative Tour Packages in addition to increasing the number of tourists visits also the level of customer satisfaction is increasing because it does not accumulate on one Destination that is Parangtris Beach can be distributed to this destination equally.

The results of this research area is the Parangtritis Beach could be developed into an alternative tour package based on the study of researcher. Be a tour package: 1 . Nature, include: Parangwedang bathing place, Depok Beach, Parangendog Beach, Gumuk Pasir and Museum Gumuk Pasir, 2. Religion : Makam Syeh Bela Belu and Makam Syeh Maulana Maghribi, 3. History : Gua Jepang, 4. Culture : Cepuri Watu Gilang.
\end{abstract}

Keywords : Tour package, nature, religi, history, culture, history

\section{PENDAHULUAN}

Daerah Istimewa Yogyakarta sebagai wilayah budaya dan wilayah pariwisata merupakan salah satu daerah tujuan wisata utama di Indonesia. Propinsi ini berbatasan langsung dengan Provinsi Jawa Tengah dan merupakan pusat kebudayaan Jawa yang berpusat di Kraton di Pusat Kota Yogyakarta. Daerah Istimewa Yogyakarta memiliki lima daerah administratif, yaitu Kota Yogyakarta, Kabupaten Sleman,
Kabupaten Kulonprogo, Kabupaten Bantul dan Kabupaten Gunung Kidul. Kelima wilayah administratif di Daerah Istimewa Yogyakarta mempunyai keunikan masingmasing dalam hal kegiatan kepariwisataan. Untuk Kabupaten Bantul khususnya, ada beberapa destinasi wisata alam yang mulai dirintis upaya pengembangannya yaitu: Pantai Parangtritis, Pantai Samas, Pantai Pandansimo, Gua Selarong dan kompleks Makam Raja - raja Mataram (KMRM) di 
Imogiri dan beberapa destinasi wisata lain. Dari beberapa destinasi wisata tersebut, pantai Parangtritis adalah salah satu destinasi wisata yang menempati urutan atas dilihat dari jumlah wisatawan yang datang karena didalamnya mempunyai potensi - potensi yang cukup menarik perhatian wisatawan.

Melihat potensi Pantai Parangtritis sebagai salah satu destinasi wisata pantai yang paling banyak menyita perhatian dengan berbagai ragam potensi daya tariknya, yang tidak semata - mata berbasis wisata pantai, melainkan merupakan perpaduan wisata alam dan wisata budaya. Pada hakikatnya pengemasan paket wisata di kawasan destinasi Parangtritis yang diarahkan agar dapat mengoptimalkan dampak positif dan meminimalkan dampak negatif dengan target pengembangan. Destinasi yang berada di kawasan Pantai Parangtritis belum menjadi tujuan alternatif karena kalah bersaing dengan Pantai Parangtritis, sehingga dapat dibuat paket wisata alternatif untuk wisatawan yang akan berkunjung ke kawasan Pantai Parangtritis.

\section{LITERATURE REVIEW}

Pariwisata adalah kegiatan dinamis yang melibatkan banyak manusia serta menghidupkan berbagai bidang usaha (Ismayanti, 2010)

1. Wisata adalah kegiatan perjalanan yang dilakukan oleh seseorang atau sekelompok orang dengan mengunjungi tempat tertentu untuk tujuan rekreasi, pengembangan pribadi, atau mempelajari keunikan daya tarik wisata yang dikunjungi dalam jangka waktu yang terbatas (Undang - undang Kepariwisataan Pasal 1, 2009).
2. Pariwisata adalah berbagai macam kegiatan wisata dan didukung berbagai fasilitas serta layanan yang disediakan oleh masyarakat, pengusaha, Pemerintah, dan Pemerintah Daerah (Undang - undang Kepariwisataan Pasal 1, 2009).

3. Potensi adalah kemampuan yang mempunyai kemungkinan untuk dikembangkan (Josef Alfonsius Gadi Djou, 2013).

4. Daya Tarik Wisata adalah segala sesuatu yang memiliki keunikan, keindahan, dan nilai yang berupa keanekaragaman kekayaan alam, budaya, dan hasil buatan manusia yang menjadi sasaran atau tujuan kunjungan wisatawan (Undang undang Kepariwisataan Pasal 1, 2009).

5. Daerah tujuan pariwisata yang selanjutnya disebut Destinasi Pariwisata adalah kawasan geografis yang berada dalam satu atau lebih wilayah administratif yang di dalamnya terdapat daya tarik wisata, fasilitas umum, fasilitas pariwisata, aksesibilitas, serta masyarakat yang saling terkait dan melengkapi terwujudnya kepariwisataan (Undang - undang Kepariwisataan Pasal 1, 2009).

6. Kawasan Strategis Pariwisata adalah kawasan yang memiliki fungsi utama pariwisata atau memiliki potensi untuk pengembangan pariwisata yang mempunyai pengaruh penting dalam satu atau lebih aspek, seperti pertumbuhan ekonomi, sosial dan budaya, pemberdayaan sumber daya alam, daya dukung lingkungan hidup, serta pertahanan dan keamanan 
(Undang - undang Kepariwisataan Pasal 1, 2009).

7. Paket wisata adalah adalah produk jasa, produk tidak berwujud (intangible product) dan wisatawan yang membeli produk paket wisata, hakikatnya lebih bersifat membeli harapan, menggan-tungkan agar pelaksanaan perjalanan wisata akan sesuai dengan harapan (Nuriata, 2014).

8. Pariwisata alternatif merupakan suatu pengembangan pariwisata yang berfokus pada kegiatan pelestarian lingkungan dan budaya lokal, serta dalam kegiatan tersebut melibatkan partisipasi dari masyarakat (I Gede Samiarta dan I Gst. Agung Oka Mahagangga, 2016).

9. Jasa Perjalanan Wisata / Tour adalah usaha biro perjalanan wisata dan usaha agen perjalanan wisata. Usaha biro perjalanan wisata meliputi usaha penyediaan jasa perencanaan perjalanan dan/jasa pelayanan dan penyelenggaraan perjalanan ibadah. Usaha agen perjalanan wisata meliputi usaha jasa pemesanan sarana, seperti pemesanan tiket dan pemesanan akomodasi, serta pengurusan dokumen perjalanan. Untuk menggambarkan tentang pola keterkaitan kegiatan yang terjadi, baik keterkaitan usaha maupun kegiatan kedepan maupun kebelakang, dapat diuraikan rangkaian kegiatan sistemik sebagai berikut (Ismayanti, 2010):

a. Seorang wisatawan sebelum mengunjungi suatu destinasi pasti akan membutuhkan informasi mengenai destinasi yang akan dikunjungi. b. Calon wisatawan tersebut akan membutuhkan agen perjalanan wisata (travel agent) dan moda transportasi yang akan digunakan, sehingga industri perjalanan (travel industries) akan ikut berkembang.

c. Pada saat wisatawan sampai di destinasi, wisatawan akan membutuhkan fasilitas untuk menginap (akomodasi) serta makan dan minum, sehingga industri perhotelan dan usaha restoran akan menjadi berkembang). Faktor - faktor internal yang menjadi penentu dari tingkat kondisi daya dukung lingkungan dalam suatu destinasi pariwisata adalah sebagai berikut ( Bambang Sunaryo, 2013) :

1) Daya dukung sosial

Struktur sosial dan ketahanan masyarakat di suatu destinasi memiliki peran penting dalam nmenentukan tingkat daya serap destinasi terhadap wisatawan untuk mengunjunginya.

2) Daya dukung budaya

Karakteristik dan ketahanan sosial-budaya dari suatu destinasi wisata juga memiliki peran yang sangat menentukan dalam menyerap dampak dari kunjungan wisatawan ke destinasi tersebut. Secara teoritik, karakteristik sosial-budaya yang unik ( lain dari pada umumnya) akan memiliki peluang lebih besar dalam menarik jumlah wisatawan untuk datang berkunjung

3) Daya dukung fisik

Daya dukung lingkungan suatu destinasi, baik pada aspek biotik maupun aspek abiotik (phisik) 
juga akan sangat menentukan jumlah maksimum wisatawan yang dapat ditampung oleh destinasi tersebut.

4) Daya dukung ekonomi

Secara luas dapat dikemukakan bahwa daya dukung ekonomi di suatu destinasi merupakan parameter pokok dalam menentukan besaran investasi pengembangan kepariwisataan di suatu destinasi,

5) Daya dukung politik

6) Daya dukung politik terhadap keberadaan industri kepariwisataan di suatu destinasi pada hakekatnya merupakan gambaran derajad legitimasi dan akseptabilitas dari masyarakat yang sekaligus mencerminkan harapan, cita-cita dan mandat dari masyarakat pada kinerja kepariwisataan di suastu destinasi wisaata.

7) Daya dukung sumberdaya lokal Daya dukung lingkungan yang berupa ketersediaan sumberdaya lokal destinasi, baik yang berupa tenaga kerja, sumber pendanaan, penyediaan lahan maupun peran aktif para pelaku usaha kepariwisataan dari masyarakat setempat berpengaruh terhadap keberlanjutan pengembangan kepariwisataan di destinasi tersebut. (Bambang Sunaryo, 2013)

10. Paket wisata (package tour/inclusive tour) diartikan sebagai suatu perjalanan wisata dengan satu atau beberapa tujuan kunjungan yang disusun dari berbagai fasilitas perjalanan tertentu dalam suatu acara perjalanan yang tetap, serta dijual sebagai harga tunggal yang menyangkut seluruh komponen dari perjalanan (Nuriata, 2014).

11. Jenis tour berdasarkan tipologi wisata dikenal dengan nama, mass tour, alternative tour dan special interest tour (Nuriata, 2014)

a. Mass Tour

1) Paket berlaku untuk wisatawan umum, semua wisatawan dapat mengikuti acara perjalanan wisata.

2) Fasilitas wisata dipersiapkan baik/prima

3) Kepuasan diukur atas harapan dari itinerary dan kenyataan yang diterima dalam pelaksanaan

b. Alternative tour

1) Paket berlaku untuk wisatawan umum dengan pilihan wisatawan: kesenangan/hobi/keilmuan mengikuti acara perjalanan wisata.

2) Fasilitas wisata dipersiapkan baik/prima.

3) Kepuasan diukur atas harapan dari itinerary dan kenyataan dari program alternatif yang ditemukan dalam pelaksanaan perjalanan

c. Special interest tour

1) Tidak berlaku umum dan bukan alternatif, merupakan tour dengan minat khusus.

2) Kepuasan yang utama akan diperoleh bila minat khusus tercapai, kenyataan yang terjadi lebih dari yang diharapkan

3) Fasilitas tidak menjadi persyaratan utama, cukup memanfaatkan fasilitas yang ada. 


\section{METODE PENELITIAN}

Penelitian kualitatif adalah penelitian yang bermaksud untuk memehami fenomena tentang apa yang dialami oleh subyek penelitian secara holistic dan dengan cara deskrispis dalam bentuk kata kata dan bahasa pada suatu konteks khusus yang alamiah dan dengan memanfaatkan berbagai metode ilmiah (Lexy J Moleong, 2010).

\section{HASIL PENELITIAN DAN PEMBAHASAN}

\section{Hasil Penelitian}

\section{Analisa SWOT}

Salah satu strategi dalam upaya untuk menghadapi pertumbuhan, pengembangan dan pemasaran Destinasi adalah dengan sebuah analisis SWOT. Analisis SWOT adalah analisis yang menguraikan tentang Strength, (kekuatan suatu destinasi sebagai unggulan), Weakness (kelemahan suatu destinasi sebagai kekurangan) Opportunity (peluang yang dimanfaatkan secara lebih optimal), dan Threat (ancaman dari luar yang dapat menambah nilai negatif pada suatu destinasi). Adapun analisis SWOT potensi destinasi wisata kawasan Pantai Parangtritis adalah sebagai berikut:

1. Pemandian Parangwedang

2. Situs Gua Jepang

3. Gumuk Pasir dan Museum Gumuk Pasir

4. Makam Syeh Bela Belu

5. Makam Syeh Maulana Maghribi

6. Pantai Depok

7. Pantai Parangendog

8. Cepuri Watu Gilang

\begin{tabular}{|c|c|c|c|c|c|}
\hline No & Komponen & $\mathbf{S}$ & $\mathbf{W}$ & $\mathbf{O}$ & $\mathbf{T}$ \\
\hline 1 & $\begin{array}{l}\text { Pemandian } \\
\text { Parang } \\
\text { wedang }\end{array}$ & 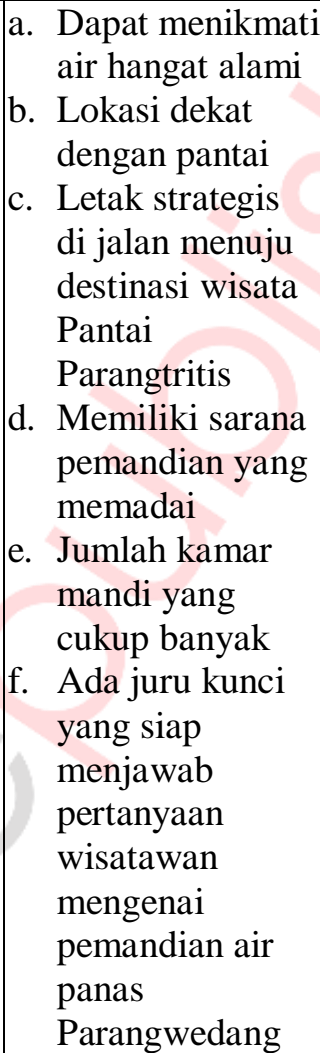 & $\begin{array}{l}\text { a. Kurangnya } \\
\text { promosi } \\
\text { Pengembangan } \\
\text { yang sifatnya } \\
\text { spontan di } \\
\text { masa lalu } \\
\text { memerlukan } \\
\text { penataan ulang } \\
\text { sehingga } \\
\text { memerlukan } \\
\text { biaya lebih besar } \\
\text { bempat parkir } \\
\text { belum tersedia } \\
\text { secara } \\
\text { memadai } \\
\text { c. Belum adanya } \\
\text { paket wisata } \\
\text { yang menjual } \\
\text { potensi di } \\
\text { kawasan } \\
\text { destinasi } \\
\text { wisata Pantai } \\
\text { Parangtritis }\end{array}$ & \begin{tabular}{|l|} 
a. \\
taman kecil \\
yang \\
membuat \\
parangwedang \\
terkesan \\
tertata rapi \\
b. Harga tiket \\
masuk \\
terjangkau \\
c. Air hangat \\
yang ada dapat \\
menyembuhka \\
n penyakit
\end{tabular} & 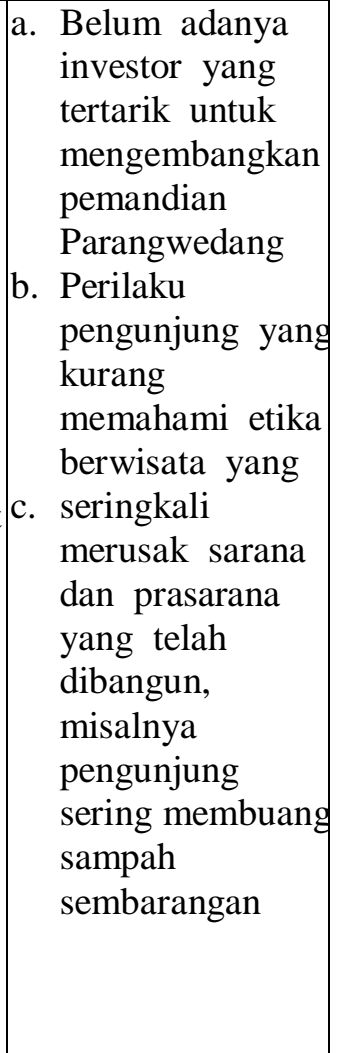 \\
\hline 2 & $\begin{array}{l}\text { Situs Gua } \\
\text { Jepang }\end{array}$ & $\begin{array}{l}\text { a. Merupakan } \\
\text { situs bersejarah } \\
\text { masa }\end{array}$ & $\begin{array}{l}\text { a. Belum dikelola } \\
\text { dengan baik } \\
\text { oleh instansi }\end{array}$ & \begin{tabular}{|l|} 
a. Pemandangan \\
yang menarik \\
di sekitar
\end{tabular} & $\begin{array}{l}\text { a. Akses yang sulit } \\
\text { ditempuh jika } \\
\text { menggunakan }\end{array}$ \\
\hline
\end{tabular}




\begin{tabular}{|c|c|c|c|c|c|}
\hline No & Komponen & $\mathbf{S}$ & $\mathbf{W}$ & $\mathbf{O}$ & $\mathbf{T}$ \\
\hline & & \begin{tabular}{|l} 
penjajahan \\
jepang \\
b. Wisatawan \\
dapat \\
menikmati \\
pemandangan \\
alam lepas \\
pantai dari bukit \\
sekitar gua \\
c. Wisatawan \\
dapat \\
menikmati \\
sunset dari atas \\
bukit \\
d. Keadaan sekitar \\
lokasi yang \\
masih alami, \\
udara yang \\
belum tercemar \\
e. Merupakan \\
wisata minat \\
khusus yang \\
sangat menarik
\end{tabular} & \begin{tabular}{|l} 
b. \\
borkait \\
yandisi gua \\
ditangani \\
secara \\
professional \\
c. Belum adanya \\
sarana dan \\
prasarana
\end{tabular} & $\begin{array}{l}\text { destinasi } \\
\text { b. Pemasaran } \\
\text { dapat } \\
\text { dilakukan } \\
\text { untuk } \\
\text { menarik } \\
\text { investor } \\
\text { dalam } \\
\text { pembangunan } \\
\text { saran dan } \\
\text { prasarana } \\
\text { c. Terdapat } \\
\text { tempat lapang } \\
\text { dapat berguna } \\
\text { untuk } \\
\text { perkemahan }\end{array}$ & kendaraan \\
\hline 3 & $\begin{array}{l}\text { Gumuk } \\
\text { pasir dan } \\
\text { Museum } \\
\text { Gumuk } \\
\text { pasir }\end{array}$ & $\begin{array}{l}\text { a. Hanya ada } 4 \\
\text { negara di dunia } \\
\text { yang } \\
\text { mempunyai } \\
\text { gumuk pasir } \\
\text { b. Terdapat } \\
\text { museum gumuk } \\
\text { pasir sebagai } \\
\text { tempat informas } \\
\text { mengenai gumuk } \\
\text { pasir } \\
\text { c. Potensi pasir } \\
\text { yang berlimpah } \\
\text { dan membentuk } \\
\text { hamparan luas } \\
\text { dapat dijadikan } \\
\text { lokasi berbagai } \\
\text { kegiatan } \\
\text { d. Potensi } \\
\text { kelangkaan } \\
\text { gumuk pasir } \\
\text { dapat dijadikan } \\
\text { aset utama } \\
\text { dalam } \\
\text { pengembangan } \\
\text { destinasi wisata } \\
\text { Pantai } \\
\text { Parangtritis }\end{array}$ & $\begin{array}{l}\text { a. Kurangnya } \\
\text { promosi } \\
\text { b. Kurangnya staf } \\
\text { ahli dalam } \\
\text { pengelolaan } \\
\text { museum. } \\
\text { c. Struktur } \\
\text { organisasi } \\
\text { yang masih } \\
\text { belum jelas } \\
\text { sehingga } \\
\text { operasioal } \\
\text { pengelolaan } \\
\text { museum } \\
\text { gumuk pasir } \\
\text { terkesan } \\
\text { tumpang tindih }\end{array}$ & $\begin{array}{l}\text { a. Menambah } \\
\text { tingkat } \\
\text { kunjungan } \\
\text { wisatawan } \\
\text { yang akan } \\
\text { berkunjung } \\
\text { ke destinasi } \\
\text { wisata } \\
\text { kawasan } \\
\text { Pantai } \\
\text { Parangtritis } \\
\text { b. Tanpa } \\
\text { mengganggu } \\
\text { keseimbangan } \\
\text { ekologi } \\
\text { gumuk pasir, } \\
\text { gumuk pasir } \\
\text { sangat } \\
\text { potensial } \\
\text { untuk } \\
\text { dikembangka } \\
\text { n menjadi } \\
\text { bagian dari } \\
\text { objek wisata }\end{array}$ & $\begin{array}{l}\text { a. } \text { Masyarakat } \\
\text { belum } \\
\text { sepenuhnya } \\
\text { menyadari daya } \\
\text { tarik gumuk } \\
\text { pasir dalam } \\
\text { kerangka } \\
\text { pariwisata } \\
\text { secara } \\
\text { menyeluruh } \\
\text { b. Pembangunan } \\
\text { yang } \\
\text { berlebihan, } \\
\text { tidak seimbang, } \\
\text { tidak terencana } \\
\text { dengan baik dan } \\
\text { hanya } \\
\text { mementingkan } \\
\text { sektor } \\
\text { pembangunan } \\
\text { sarana dan } \\
\text { prasarana } \\
\text { wisata saja } \\
\text { dikhawatirkan } \\
\text { akan } \\
\text { mengganggu } \\
\text { ekosistem } \\
\text { gumuk pasir }\end{array}$ \\
\hline 4 & Pantai & a. Lokasi yang & a. Promosi yang & a. Menambah & a. Bahaya air \\
\hline
\end{tabular}




\begin{tabular}{|c|c|c|c|c|c|}
\hline No & Komponen & $\mathbf{S}$ & $\mathbf{W}$ & $\mathbf{O}$ & $\mathbf{T}$ \\
\hline & $\begin{array}{l}\text { Parangendo } \\
\mathrm{g}\end{array}$ & $\begin{array}{l}\text { mudah dicapai } \\
\text { b. Dekat dengan } \\
\text { hotel } \\
\text { c. Terdapat tempat } \\
\text { untuk berteduh }\end{array}$ & $\begin{array}{l}\text { dilakukan oleh } \\
\text { dinas } \\
\text { pariwisata } \\
\text { belum optimal } \\
\text { b. Belum dikelola } \\
\text { dengan baik } \\
\text { c. Minimnya dana } \\
\text { untuk } \\
\text { pembangunan } \\
\text { dan } \\
\text { pengembangan } \\
\text { d. Tingkat } \\
\text { keamanan } \\
\text { kurang } \\
\text { memadahi }\end{array}$ & $\begin{array}{l}\text { tingkat } \\
\text { kunjungan } \\
\text { wisatawan } \\
\text { yang akan } \\
\text { berkunjung } \\
\text { ke destinasi } \\
\text { wisata } \\
\text { kawasan } \\
\text { Pantai } \\
\text { Parangtritis } \\
\text { b. Dikembangkan } \\
\text { menjadi arena } \\
\text { renang } \\
\text { mengingat } \\
\text { area tersebut } \\
\text { terdapat kolam } \\
\text { renang }\end{array}$ & $\begin{array}{l}\text { pasang } \\
\text { b. } \text { Kurangnya } \\
\text { kesadaran } \\
\text { masyarakat } \\
\text { terhadap } \\
\text { destinasi }\end{array}$ \\
\hline 5 & $\begin{array}{l}\text { Makam } \\
\text { Syeh Bela } \\
\text { Belu }\end{array}$ & \begin{tabular}{|l} 
a. \\
Berada di atas \\
bukit serta \\
mempunyai \\
arah orientasi \\
ke laut \\
b. Merupakan \\
destinasi wisata \\
spiritual Lokasi \\
strategis \\
c. Ada sang juru \\
kunci yang \\
dapat \\
membantu \\
wisatawan \\
dalam kegiatan \\
spiritual
\end{tabular} & \begin{tabular}{|l} 
a. \\
Belum \\
optimalnya \\
promosi dan \\
informasi \\
sehingga \\
berdampak \\
pada jumlah \\
pengunjung \\
yang sedikit \\
(khususnya \\
wisatawan \\
spiritual) \\
b. Juru kunci \\
yang kurang \\
menguasai \\
tentang latar \\
belakang \\
Makam Syeh \\
Bela Belu
\end{tabular} & $\begin{array}{l}\text { a. Pemandangan } \\
\text { menuju } \\
\text { destinasi } \\
\text { menarik } \\
\text { b. Sarana dan } \\
\text { prasarana } \\
\text { memadai }\end{array}$ & \begin{tabular}{|l} 
a. Kawasan \\
tersebut mulai \\
dilirik para \\
pedagang yang \\
lebih \\
mengutamakan \\
dimensi \\
ekonomi \\
daripada \\
dimensi \\
spiritual \\
b. Letak jauh dari \\
jalan raya
\end{tabular} \\
\hline 6 & $\begin{array}{l}\text { Makam } \\
\text { Syeh } \\
\text { Maulana } \\
\text { Maghribi }\end{array}$ & \begin{tabular}{|l} 
a. \\
Lingkungan \\
sekitar bersih \\
sehingga para \\
wisatawan bisa \\
melakukan \\
kegiatan \\
spriritual secara \\
lebih baik \\
b. Terdapat tempat \\
peristirahatan \\
untuk para \\
peziarah
\end{tabular} & \begin{tabular}{|l} 
a. Wisatawan \\
harus menjaga \\
tutur kata \\
selama berada \\
di destinasi \\
b. Kurangnya \\
dana untuk \\
membuat \\
tempat parkir
\end{tabular} & $\begin{array}{l}\text { a. Tersedia } \\
\text { jaringan } \\
\text { listrik } \\
\text { b. Pemandangan } \\
\text { sepanjang } \\
\text { perjalanan } \\
\text { menarik, } \\
\text { wisatawan } \\
\text { dapat melihat } \\
\text { pemandangan } \\
\text { pantai dan } \\
\text { gumuk pasir }\end{array}$ & 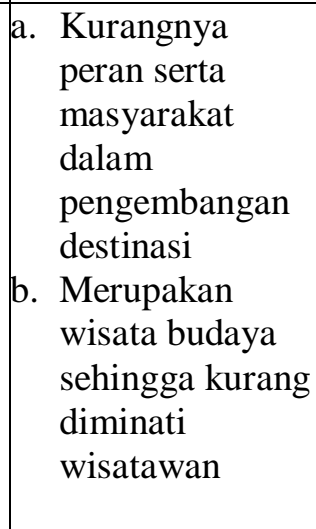 \\
\hline 7 & $\begin{array}{l}\text { Pantai } \\
\text { Depok }\end{array}$ & $\begin{array}{l}\text { a. Terdapat } \\
\text { tempat } \\
\text { pelelangan ikan } \\
\text { sehingga }\end{array}$ & $\begin{array}{l}\text { a. Pasir yang } \\
\text { membentang } \\
\text { luas jika siang } \\
\text { hari terasa }\end{array}$ & $\begin{array}{ll}\text { a. } & \text { Wisatawan } \\
\text { dapat } \\
\text { berpartisipa } \\
\text { si dengan }\end{array}$ & $\begin{array}{l}\text { a. Kerusakan } \\
\text { lingkungan } \\
\text { dikarenakan } \\
\text { wisatawan }\end{array}$ \\
\hline
\end{tabular}




\begin{tabular}{|c|c|c|c|c|c|}
\hline No & Komponen & $\mathbf{S}$ & $\mathbf{W}$ & $\mathbf{0}$ & $\mathbf{T}$ \\
\hline & & \begin{tabular}{|l} 
wisatawan \\
dapat membeli \\
ikan secara \\
langsung \\
b. Tempat parkir \\
\\
luas \\
c. Terdapat \\
penjualan \\
cinderamata \\
dalam wujud \\
makanan \\
d. Harga makanan \\
menyesuaikan \\
keinginan dari \\
wisatawan
\end{tabular} & $\begin{array}{l}\text { sangat panas } \\
\text { b. Belum } \\
\text { tersedianya } \\
\text { sarana } \\
\text { transportasi } \\
\text { langsung } \\
\text { menuju } \\
\text { destinasi }\end{array}$ & \begin{tabular}{|l} 
masyarakat \\
membantu \\
para nelayan \\
saat akan \\
berlabuh \\
b. \\
Akses \\
menuju \\
destinasi \\
mudah \\
c. Harga tiket \\
masuk \\
terjangkau
\end{tabular} & \begin{tabular}{|l} 
yang \\
membuang \\
sampah secara \\
sembarangan \\
b. Jika terjadi \\
angin besar \\
nelayan tidak \\
bisa melaut
\end{tabular} \\
\hline 8 & $\begin{array}{l}\text { Cepuri } \\
\text { Watu } \\
\text { Gilang }\end{array}$ & $\begin{array}{l}\text { a. Terdapat shelter } \\
\text { yang dapat } \\
\text { digunakan } \\
\text { wisatawan saat } \\
\text { cuaca panas } \\
\text { b. Fasilitas seperti } \\
\text { kamar mandi, } \\
\text { taman, masjid, } \\
\text { tempat parkir, } \\
\text { dan listrik telah } \\
\text { tersedia } \\
\text { c. Terdapat lahan } \\
\text { yang dapat } \\
\text { dijadikan } \\
\text { camping ground } \\
\text { d. Berbagai macam } \\
\text { festival } \\
\text { diselenggara-kan } \\
\text { di tempat ini }\end{array}$ & $\begin{array}{l}\text { a. Penerangan } \\
\text { kurang } \\
\text { maksimal }\end{array}$ & \begin{tabular}{|l} 
a. Akses \\
kendaraan \\
untuk \\
memasuki \\
destinasi \\
mudah \\
b. Banyak \\
penjual \\
souvenir \\
sekitar \\
destinasi
\end{tabular} & $\begin{array}{l}\text { a. Lahan pedagang } \\
\text { belum } \\
\text { ditentukan } \\
\text { sehingga } \\
\text { menimbulkan } \\
\text { kesan tidak } \\
\text { tertata } \\
\text { b. Kerusakan } \\
\text { lingkungan } \\
\text { akibat } \\
\text { masyarakat } \\
\text { sekitar }\end{array}$ \\
\hline
\end{tabular}

\section{PEMBAHASAN}

Dari hasil analisa dengan menggunakan SWOT maka Potensi Wisata di Parangtritis dapat dikelompokkan menjadi Paket wisata Alternatif

\section{Pertama}

\section{PAKET WISATA ALAM}

Parang wedang ,Gumuk Pasir, Pantai Depok, Pantai Parangendog

\section{Pemandian Parangwedang}

Terletak di Dusun Mancingan Desa Parangtritis dengan seluas $1140 \mathrm{~m}^{2}$, dahulu merupakan persawahan, para petani atau pemilik tanah tidak bisa menanami lahannya, kalaupun ditanami hasilnya jelek karena tanaman tumbuh tidak normal yang disebabkan oleh timbulnya air panas yang memancar dari tanah.

Sumber air panas yang paling besar diperdalam oleh masyarakat, pada saat masa Sri Sultan Hamengkubuwono VIII diberi pasak suci, pada masa Sri Sultan Hamengkubuwono IX dibangun parang wedang namun dirusak oleh penjajah, kemudian tahun 80an mulai direnovasi kembali dengan motif yang lain, kemudian tahun 86 direnovasi kembali. Parangwedang dipugar pertama kali tahun 1991. 
Parangwedang diserbu pengunjung saat hari minggu baik pribadi atau rombongan. Air pada zaman dulu oleh masyarakat digunakan untuk penyembuhan penyakit, air tidak hanya digunakan untuk mandi tetapi juga diminum. Selain itu juga ada yang mengunjungi saat Selasa dan Jum'at untuk melakukan ritual. fasilitas yang ada antara lain:

a. Kolam penampungan air hangat $8 \mathrm{x}$ 11 meter dengan kedalaman 9 meter,

b. Kemudian dialirkan ke setiap kamar mandi, air pernah diuji ada 39 macam / warna, garam minyak tanah belerang yang terbesar kandungannya.

c. Ada 10 kamar mandi hangat, namun yang difungsikan hanya 9 kamar, karena kamar mandi nomer 1 dikhususkan untuk Ngarso dalem.

d. Ada juga 3 kamar mandi air tawar.

e. Buka mulai jam 06.00 - tutup, selasa dan jum'at kliwon buka 24 jam

Retribusi untuk tambal sulam pengelola, dan retribusi tersebut untuk membayar listrik. Ada syarat tertentu untuk menggunakan air parangwedang jika akan dipakai untuk obat, misal :

a. Selama 3 bulan tidak boleh melayat

b. Tidak boleh makan emping mlinjo

c. Tidak boleh mengunjungi bayi yang baru lahir

Pengurus 6 juru kunci: Nama-nama diperoleh dari pemberian Ngarsodalem, kerena para juru kunci mengikuti tes terlebih dahulu di kraton yogyakarta dan mereka mendapatkan gelar sebagi berikut :
a. Parang Pertomo
b. Parang Sujarwo
c. Parang Tirto
d. Parang Panukmo
e. Parang Sudiro
f. Parang Prawoto

Pemandian Parangwedang dapat dijadikan alternatif paket wisata karena memliki daya tarik tersendiri bagi wisatawan yang datang ke pemandian tersebut dapat mengetahui dan mempelajari pemanfaatan sumber air panas alami sebagai tempat pemandian atau pesanggrahan tradisional sejak dahulu kala.

\section{Pantai Depok}

Pantai Depok adalah pantai yang memiliki keunikan tersendiri, selain pemandangan pantai, para wisatawan dapat berwisata kuliner. Tak jauh dari pantai ini, wisatan dapat menikmati panorama gumuk pasir satu - satunya di kawasan Asia Tenggara.

Di antara pantai - pantai lain di wilayah Bantul, Pantai Depok dirancang menjadi pusat wisata kuliner menikmati seafood. Di pantai ini, tersedia sejumlah warung makan tradisional yang menjajakan seafood, berderet tak jauh dari bibir pantai. Beberapa warung makan dirancang menghadap ke selatan, sehingga sambil menikmati hidangan laut, wisatawan dapat melihat pemandangan laut lepas dengan ombak yang besar.

Nuansa khas warung makan pesisir dan aktivitas nelayan Pantai Depok telah berkembang sejak beberapa tahun lalu. Menurut cerita, sekitar tahun 1997, beberapa nelayan yang berasal dari Cilacap menemukan tempat pendaratan yang memadai di Pantai Depok. Para nelayan itu membawa hasil tangkapan yang cukup banyak sehingga menggugah warga Pantai Depok yang umumnya berprofesi sebagai petani lahan pasir untuk ikut menangkap ikan.

Sejumlah warga pantai pun mulai menjadi "tekong", istilah lokal untuk menyebut pencari ikan. Para tekong melaut 
dengan bermodal perahu bermotor yang dilengkapi cadik. Kegiatan menangkap ikan dilakukan hampir sepanjang tahun, kecuali pada hari-hari tertentu yang dianggap keramat, yaitu selasa kliwon dan jumat kliwon. Di luar musim paceklik ikan yang berlangsung antara bulan Juni - September, jumlah hasil tangkapan cukup lumayan.

Karena jumlah tangkapan yang cukup besar, maka warga setempat membuka Pangkalan Pendaratan Ikan (PPI) yang kemudian dilengkapi dengan Tempat Pelelangan Ikan (TPI) bernama Mina Bahari 45. Tempat pelelangan ikan di pantai ini menerima setoran ikan yang ditangkap oleh nelayan di pantai-pantai lain.

Seiring semakin banyak pengunjung pantai yang berjarak 1,5 kilometer dari Parangtritis, maka dibukalah warung makan makan seafood. Umumnya, warung makan yang berdiri di pantai ini menawarkan nuansa tradisional. Bangunan warung makan tampak sederhana dengan atap limasan, sementara tempat duduk dirancang lesehan menggunakan tikar dan meja - meja kecil. Meski sederhana, warung makan tampak bersih dan nyaman.

\section{Gumuk Pasir (Museum Geografi)}

Terletak disepanjang Pantai

Parangtritis sampai muara sungai Opak (Pantai Depok). Lokasi gumuk pasir aktif terletakdi kawasan sisi timur yaitu di sekitar Pantai Parangkusumo, sedangkan gumuk pasir pasif terletak di kawasan sisi barat sampai di Pantai Depok.

Di sebelah barat Pantai Parangkusumo, terhampar gumuk pasir yang luas, yang merupakan warisan dunia (World Heritage), di dunia hanya ada 4 negara, salah satunya adalah di Pantai Parangtritis. Disini telah dirintis pembangunan Laboraturium, ekosistem pesisir, di dalamnya pengunjung dapat mempelajari ilmu kebumian serta fenomena alam pesisir lain.

Gumuk Pasir merupakan suatu fenomena alam yang sangat langka untuk daerah yang beriklim tropis seperti di Indonesia khususnya dan Asia Tenggara pada umumnya. Gumuk pasir juga merupakan salah satu ekosistem pantai, gumuk pasir merupakan akumulasi pasir lepas berbentuk gundukan teratur, hasil angin yang bertiup searah dan terusmenerus pada suatu daerah. Proses pembentukan gumuk pasir disebabkan oleh beberapa faktor yaitu :

a. Tersedianya material berukuran pasir dalamjumlah banyak.

b. Adanya tenaga pengangkut berupa angin yang cukup kencang.

c. Adanya musimkering yang tegas dalamsatu tahunnya.

d. Tidak adanya penghalang di sepanjang pantai bagian depan.

Gumuk pasir tipe barchan (berbentuk sabit) dan longitudinal (bukit yang memanjang) menurut aktivitasnya termasuk jenis gumuk pasir aktif. Di Pantai Parangtritis terdapat $25 \%$ atau sekitar 75 hektar lahan berupa gumuk pasir yang bersifat aktif. Proses pembentukan gumuk pasir dan jejak pengendapan misalnya struktur pengendapatan silang-siur dan jejak gerak angin dapat diamati dengan baik. Gumuk pasir pasif menempati sisi barat kawasan sampai Kali Opak, dengan didominasi oleh bentuk parabolic dan sisir. Gumuk pasir tipe ini dapat dimanfaatkan sebagai lahan pertanian.

Pelestarian gumuk pasir merupakan bagian dari pelestarian lingkungan Parangtritis sehingga keberadaan gumuk 
pasir perlu dipertahankan dan dapat dijadikan suatu laboratorium alam maupun cagar alam ilmiah.

a. Laboratorium gumuk pasir dibuat karena berapa hal, antara lain :

1) Pemerintah RI terkait dengan penandatanganan kesepakatan dunia untuk menjaga kelestarian lingkungan atau efek rumah kaca atau pemanasan bumi secara global di Brazil.

2) Pemerintah RI menyusun agenda 21 khususnya kerusakan ekosistem pesisir dan laut, lalu pemerintah RI menyatakan siap mendirikan pusat riset tentang pengelolaan pesisir laut, kemudian dilakukan seminar ditingkat Nasional.

3) BAKOSURTANAL, UGM, PEMDA DIY bersinergi untuk mempertajam misi, visi lembaga tersebut, yang melalui seminar yang terakhir di Hotel Purosani tahun 2001.

b. Program yang dilakukan

1) Dilakukan kajian yang bersifat akademis dan harus dilanjutkan diterapkan untuk pemberdayaan masyarakat

2) Tahun 2006 mulai pemodelan fishingground di Parangtritis dan pantai selatan Pulau Jawa yang diawali dengan pengumpulan data-data hasil penangkapan ikan yang ada.

Wisatawan yang berkunjung ke museum gumuk pasir dapat mempelajari proses fenomena alam berupa pergerakan pasir di alam yang membentuk padang pasir luas yang berpindah-pindah selama bertahun - tahun lamanya.

\section{Pantai Parangendog}

Masih termasuk di Kawasan Parangtritis merupakan pantai paling timur dari deretan pantai selatan yang ada di wilayah Kabupaten Bantul serta mempunyai kolam renang Parangendog yang terletak di Dusun Parangendog, Desa Parangtritis, merupakan pemandian air tawar yang dekat dengan Pantai Parangkusumo.

Fasilitas yang ada :

- Kolam renang berukuran 1,5 x 22,25 m dengan kedalaman 1,5 m

- Kolam ikan berukuran 4,4 x 8,5 m

Wisatawan disamping dapat menikmati keindahan pantai dapat juga mempelajari pemanfaatan sumber mata air alami sebagai tempat pemandian umum.

\section{Kedua \\ PAKET WISATA RELIGI}

Makam Syeh Bela Belu dan Makam Syeh Maulana Magribi

\section{Makam Syeh Bela Belu}

Syeh Bela Belu termasuk keluarga Kerajaan Majapahit yang giat menyebarkan Agama Islam. Sebagai seorang ulama beliau sering berpindah-pindah dari satu daerah ke daerah lain di Pulau Jawa. Suatu ketika beliau sampai di Parangtritis di tempat itu beliau menetap sampai akhir hayatnya dan atas kehendak pengikutnya beliau dimakamkan di atas bukit dengan ketinggian pagar tembok setinggi $1.5 \mathrm{~m}$. Untuk mencapai makam ini harus melewati tangga batu bata selebar $160 \mathrm{~cm}$, jarak dari bawah sekitar 326 m, Desa Parangtritis. Acara yang diselenggarakan di makam ini antara lain adalah ziarah pada malam selasa dan jum'at kliwon serta 1 suro.

Menurut legenda, Syeikh Bela Belu merupakan penganut Ajaran Hindu - Budha 
yang berasal dari Kerajaan Majapahit. Beliau dalam usaha mempertahankan ajaran agamanya pernah bertaruh "memancing" dengan Syeikh Maulana Maghribi dengan janji bahwa yang kalah dalam taruhan harus mengikuti agama yang menang. Pada akhirnya ternyata Syeikh Maulana Maghribi lebih unggul dari Syeikh Bela Belu sehingga Syeikh Bela Belu masuk Agama Islam.

Makam Syeikh Bela Belu berada diatas perbukitan dan berada disebelah Barat dari Makam Syeikh Maulana Maghribi. Disana Wisatawan dapat mengetahui adanya dan asal penyebaran agama Islam di daerah Parangtritis. Mengetahui keragaman tipe-tipe lanskap di Kawasan Parangtritis dengan melihat dari ketinggian perbukitan.

\section{Makam Syeh Maulana Maghribi}

Makam Maulana Maghribi berada di atas perbukitan di desa Mancingan Parangtritis. Jika ditarik garis, maka Makam Maulana Maghribi ini berada dalam segitiga imajiner yang menghubungkan komplek Cepuri Watu Gilang, kompleks Makam Maulana Magribi, serta kompleks Makam Syeikh Bela Belu.

Syeh Maulana Maghribi adalah pedagang dari negeri Arab yang giat menyebarkan Agama Islam disetiap tempat yang disinggahi termasuk di Desa Parangtritis. Sampai akhir hayatnya Syeh Maulana Maghribi menetap di Parangtritis dan dimakamkan diatas bukit yang terletak di Pedukuhan Mancingan, desa Parangtritis. Makam beliau terletak di atas bukit dengan ketinggian 42 meter. Untuk menuju keatas melalui tangga batu bata selebar $190 \mathrm{~cm}$ sepanjang 265 meter. Acara yang diselenggarakan dimakam ini antara lain : ziarah kubur dilakukan setiap selasa dan jum'at kliwon serta setiap tanggal 1 suro, seperti halnya Makam Syeh Bela - Belu, wisatawan yang datang mengunjungi makam Syeh Maulana Magribi dapat mengetahui adanya dan asal penyebaran Agama Islam di daerah Parangtritis dan menikmati pemandangan dari perbukitan.

\section{Ketiga}

\section{PAKET WISATA SEJARAH}

Situs Gua Jepang

\section{Situs Gua Jepang}

Situs Gua Jepang terletak di wilayah Kecamatan Pundong, Kabupaten Bantul merupakan kompleks pertahanan peninggalan tentara jepang tahun 1942-1945 pada saat perang dunia II.

Pada saat ini keadaan bangunan dan lingkungan gua masih relatif baik dan hanya beberapa saja yang mengalami kerusakan dan tertimbun tanah. Sebagai salah satu dari sekian banyak tinggalan sejarah yang erat kaitannya dengan perjalanan sejarah bangsa, khususnya untuk wilayah DIY, maka keberadaan gua tersebut perlu dijaga kelestariaannya sebagai aset pariwisata yang saat ini belum dikembangkan karena seorang wisatawan disamping mengetahui secara langsung gua tersebut, wisata tersebut juga bisa dikatakan wisata tracking dan melihat keindahan lepas pantai dari gua tersebut.

Pada tahun 1942 tentara jepang masuk diwilayah Indonesia dalam rangka memenuhi impian pemerintahannyau ntuk membentuk imperium dan hegemoni bangsa Jepang di Asia/ lebih dikenal dengan nama "Kemakmuran bersama Asia"

Masuknya Jepang di Indonesia ini diawali dengan mendaratnya Jepang di Balikpapan pada tanggal 20 Januari 1942, pendudukan ini kemungkinan besar berkaitan dengan bahan bakar minyak yang 
ditambang di sana, sebagai persiapan untuk mendukung bahan bakar. Selanjutnya Jepang menduduki Pontianak, Martapura dan palembang. Setelah menduduki Kalimantan dan Sumatra, maka selanjutnya Jepang mengarahkan sasarannya ke Jawa Barat atau tepatnya di daerah Eretan Wetan 1 Maret 1942.

Di wilayah Jawa tengah, Jepang mendaratkan pasukan pertamanya di daerah Blora, Purwodadi, Salatiga, Ambarawa dan beberapa kota lain. Adapun kota Yogyakarta diduduki Jepang pada tanggal 5 Maret 1942

Pada saat pendudukan inilah, tentara Jepang banyak membangun daerah pertahanan, baik yang berada di daerah pegunungan (Kaliurang), pesisir (Parangtritis) atau daerah lain yang dianggap strategis (lapangan terbang Maguwo dan sekitarnya). Di daerah pesisir Yogyakarta, fasilitas perlindungan dan pertahanan tentara Jepang ditemukan di Utara Pantai Parangtritis, seluruhnya berjumlah 19 gua pertahanan (satu diantaranya agak jauh dari 18 gua lainnya). Pemilihan daerah ini sangat ideal bagi pertahanan dan pengintaian, karena dari daerah ini kita dapat melihat langsung Pantai Parangtritis hingga ke arah barat Sungai Opak, oleh sebab itu situs gua Jepang dapat dijadikan alternatif pembuatan paket wisata untuk kawasan Parangtritis

\section{Keempat}

\section{PAKET WISATA BUDAYA}

Cepuri Watu Gilang

\section{CEPURI WATU GILANG}

Cepuri Watu Gilang dipercaya adalah sebuah petilasan, petilasan tersebut dipercaya sebagai tempat pertemuan antara pendiri Kerajaan Mataram yaitu Panembahan Senopati dan penguasa pantai selatan yaitu Ratu Kidul, dalam proses pendirian kerajaan Mataram Panembahan Senopati, kedua tokoh tersebut bertemu dan menghasilkan sebuah perjanjian antara kedua tokoh tersebut untuk saling membantu menurut sebuah legenda. Pada saat mendirikan Kerajaan Mataram yang beliau pimpin, Panembahan Senopati akan dibantu dan dijaga oleh penguasa pantai selatan dalam mendirikan Kerajaan Mataram.

Di Cepuri Watu Gilang wisatawan yang datang melakukan berziarah spiritual dengan dibantu para juru kunci yang ada. Di kawasan ini juga wisatawan dapat melihat berbagai macam upacara labuhan oleh keraton Yogyakarta. Tanah di dalam Kompleks Cepuri Watu Gilang dan sekitarnya merupakan tanah magersari atau tanah milik Kraton Yogyakarta.

\section{KESIMPULAN, KETERBATASAN DAN REKOMENDASI \\ Kesimpulan}

Dengan menurunnya jumlah wisatawan akibat pasca banjir cempaka yang berdampak pada kunjungan wisatawan ke destinasi wisata Parangtritis. Hal ini menjadikan sektor pariwisata Yogyakarta mengalami penurunan. Guna peningkatan wisatawan kembali ke Parangtritis maka peneliti mengambil kesimpulan

1. Parangtritis mempunya potensi wisata yang beragam 1.Wisata Alam 2.Wisata Religi 3.Wisata Sejarah.

2. Tour Operator / Usaha Jasa Perjalanan Wisata belum berkreasi untuk membuat paket wisata alternatif di kawasan Parangtritis

3. Kawasan wisata Parangtritis belum menyediakan saran prasana dan 
fasilitas yang memadai dan standard untuk wisatawan.

4. Lingkungan sosial belum ditata sehingga faktor keamanan dan kenyamanan dapat dijaga sehingga wisatawan lebih betah berlama-lama tinggal di Parangtritis.

5. Faktor aksebilitas dan faktor transportasi, telekomunikasi dan fasilitas rekreasi serta informasi belum tersedia secara memadai di Parangtritis.

6. Pembutana paket wisata alternatif belum dibuat secara optimal oleh tour operator/Usaha Jasa Perjalanan dikarenakan belum standardnya fasilitas, sarana dan prasarana serta fasilitas serta aksebilitas di kawasan Parangtritis.

Keterbatasan

Promosi pengembangan kawasan Parangtritis yang sifatnya spontan di masa lalu, maka diperlukan penataan ulang dalam hal fasilitas sarana prasarana dan informasi mengenai destinasi wisata yang ada di sekitar kawasan Pantai Parangtritis sehingga memerlukan biaya lebih besar dan juga pemeliharaan serta perbaikan sarana dan prasarana pariwisata diperlukan, aksebilitas dan transportasi umum belum tersedia serta dampak sosial dengan kehadiran wisatawan.

Rekomendasi

Penelitian lanjutan mengenai penataan kawasan Parangtritis serta program pemasaran yang berkelanjutan dengan instansi yang terkait dan Pengembangan Paket Wisata alternatif oleh tour operator /Usaha Jasa Perjalanan tentunya akan menambah jumlah wisatawan. Pendistribusian wisatawan secara merata di kawasan Parangtristis maka akan menambah daya dukung kawasan , sehingga tidak terjadi penumpukan wisatawan dalam satu lokasi karena akan menimbulkan berkurangnya kepuasan wisatawan dan berdampak berkurangnya jumlah wisatawan yang berkunjung .

\section{REFERENSI}

Bambang Sunaryo, 2013. Kebijakan Pembangunan Destinasi Pariwisata Konsep dan Aplikasinya di Indonesia. Edisi 1. Yogyakarta , Gava Media.

Dinas Pariwisata Daerah Istimewa Yogyakarta. 2016. Statistik Kepariwisataan. Edisi 1. Yogyakarta. Azzahra.

I Gede Samiarta dan I Gst. Agung Oka Mahagangga. (2016). Perkembangan Desa Wisata Di Kabupaten Badung (studi kasus desa wisata baha). Jurnal Destinasi Pariwisata. Vol. 4 No 2, 2016, 114. Ismayanti. 2010. Pengantar Pariwisata. Edisi 1. Jakarta. Grasindo

Josef Alfonsius Gadi Djou. (2016). Pengembangan 24 Destinasi Wisata Bahari, Kabupaten Ende, Kawistara. Volume 3 No. 1, 21 April 2013, 1116.

Lexy J. Moleong. 2010. Metode Penelitian Kualitatif. Bandung. Rosda.

Nuriata. 2014. Perencanaan dan Pelaksanaan Perjalanan Wisata Konsep dan Aplikasi. Edisi 1. Bandung. Alfabeta.

OKA A. Yoeti. 2008. Anatomi Pariwisata. Bandung. Angkasa.

Undang-Undang Republik Indonesia Nomor 10.Tahun 2009. 